\title{
Pulling out all the stops to make the distance: Effects of effort and optical information in distance perception responses made by rope pulling
}

\author{
Alen Hajnal ${ }^{1}$ - David A. Bunch ${ }^{1}$ - Damian G. Kelty-Stephen ${ }^{2}$
}

Published online: 16 December 2015

(C) The Psychonomic Society, Inc. 2015

\begin{abstract}
Human observers perceive distance in remarkably stable and consistent manner across response methods and experimental paradigms. Most empirical work on the problem focused exclusively on geometrical variables, such as angle of declination below the horizon (Ooi, Wu, \& He, 2001), with more recent considerations of nonvisual factors, such as effort (Proffitt, 2006). Hajnal, Bunch, and Kelty-Stephen (2014) showed that in addition to the object's physical angle of declination below the horizon, nonvisual variables related to effort were utilized when making distance estimates to objects placed on a sloped ramp. In that experiment, the horizontal ground surface was visible in the background when viewing objects placed on the sloped surface. To further investigate the joint utility of geometric and effort-based variables, we tested the effect of both classes of predictors on a natural hillside where a flat, horizontal surface was not visible in the background. This setup allowed us to evaluate whether observers rely on the same information to perceive distance on ramps versus real hills. The present research implicates the hypothesis that perceived effort and the geometry of space determine distance perception through interactions across multiple temporal scales of perceptual competence.
\end{abstract}

Keywords Perception · Distance $\cdot$ Effort $\cdot$ Angular declination $\cdot$ Geographical slant

Alen Hajnal

alen.hajnal@usm.edu

1 Department of Psychology, University of Southern Mississippi, 118 College dr, \#5025, Hattiesburg, MS 39406, USA

2 Department of Psychology, Grinnell College, Grinnell, IA, USA
Judging the distance to a target involves complex reliance on optical variables and effort. Human observers can judge accurately the absolute ground distance to objects up to $20 \mathrm{~m}$ on flat, horizontal terrain (Loomis, DaSilva, Fujita, \& Fukusima, 1992; Loomis, DaSilva, Philbeck, \& Fukusima, 1996; Rieser, Ashmead, Talor, \& Youngquist, 1990; Sinai, Ooi, \& He, 1998; and Thomson, 1983). According to the Sequential-SurfaceIntegration-Process hypothesis (SSIP; Wu, He, \& Ooi, 2007), the visual system integrates optical information in sequential fashion beginning nearest the observer and then proceeding towards the visual horizon, framing distance judgments (Gibson, 1950). The related Angular Declination Below the Horizon hypothesis (ADBH; Ooi, Wu, \& He, 2001) proposes that visual judgments of distance depend on the angular declination of their position relative to the horizon, with objects at large or small angles of declination below the visual horizon appearing closer to or farther from the observer, respectively (Fig. 1). The distance $d$ to a target corresponds to an angular declination $\alpha$ that subtends the eye height of the observer. According to this ADBH hypothesis, perceived distance $d_{P \text { erc }}$ corresponds to an optical angle $\alpha_{P}$ declining from horizon, calculable as the arctangent of eye height $h$ and distance judgment $d_{\text {Perc }}$. Veridical distance perception for a person with arbitrary eye height entails viewing a target with declination angle $\alpha$ and producing a distance judgment corresponding to $\alpha_{P}$, such that $\alpha_{P}=\alpha$, with overestimation or underestimation corresponding to $\alpha_{P}<$ or $>\alpha$, respectively. We also know that effort has a role in shaping distance perception, with increases in distance or in anticipated effort appearing to accentuate one another regardless of angular declination (Witt \& Proffitt, 2008). Of course, in environments with slopeless ground surfaces, smaller angular declination and greater effort might equally specify longer distances.

Sloped ground surfaces raise fascinating new questions that demand new ways to resolve the intertwining contributions of 


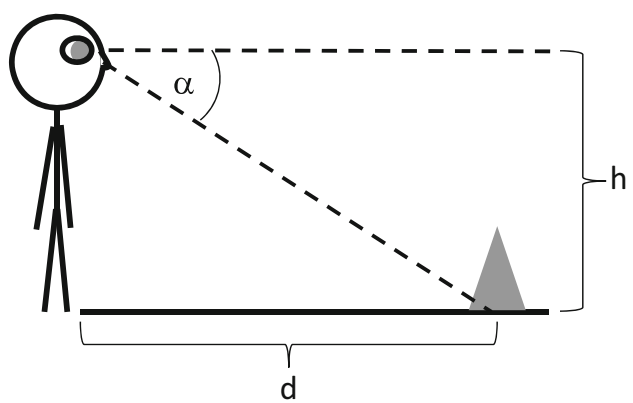

Fig. 1 The angular declination hypothesis as applied to targets on horizontal ground. The trigonometric relationship $d=h / \tan (\alpha)$ defines distance as a function of eye height and angle of declination; $d$ refers to the absolute distance to the object, $h$ corresponds to the observer's eye height, and $\alpha$ is the physical angle of declination below the horizon $(\mathrm{ADBH})$ corresponding to the location of the target object's base. Eye height appears to be a crucial, naturally available parameter useful for distance judgments (Ooi et al., 2001; Sedgwick, 1983; Stoper \& Cohen, 1986)

optical angular declinations and of effort in distance perception. For instance, slopes will diminish angular declinations for targets that are closer to the observer. Targets $T$ on a slope might appear optically as projections of the target farther away, because we have reduced the optical angle $\alpha_{P}$ where the location of the target would correspond, on unsloped ground, to a target $T$, at a greater declination $\alpha$ (Fig. 2). By reducing $\alpha_{P}$ relative to what, on flat ground, would be greater $\alpha$, slopes run the risk of inviting overestimations of distance by setting up exactly the inequality noted above, $\alpha_{P}<\alpha$. However, quite unrelated to the $\mathrm{ABDH}$ hypothesis, the grade of the slope also introduces more effort in the sort of locomotion needed to overcome that shorter distance (Proffitt, Bhalla, Gossweiler, \& Midgett, 1995; Schnall, Zadra, \& Proffitt, 2010; Witt \& Proffitt, 2008). Targets on sloped surfaces, both uphill and downhill, are perceived as being farther away than

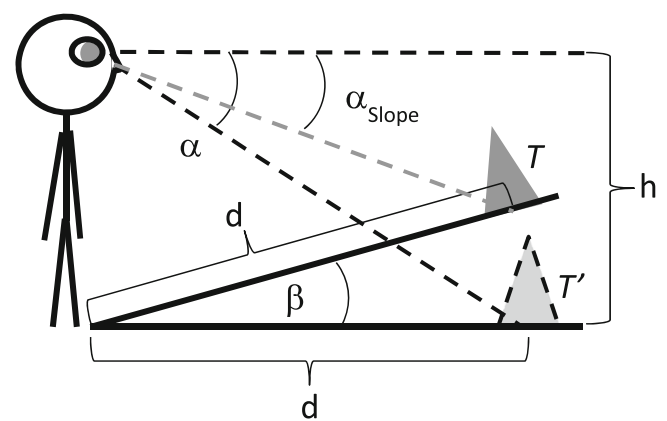

Fig. 2 Generalization of the angular declination below horizon hypothesis for sloped surface. The target object $T$ (a grey cone) is located on a geographic slant $(\beta)$, which produces an angle of declination below the horizon $\left(\alpha_{\text {Slope }}\right)$ where $\alpha_{\text {Slope }}=\tan ^{-1} \frac{h-d \sin \beta}{d \cos \beta}$. Also diagrammed is the projected angle of declination $(\alpha)$, or the angle of declination below the horizon for distance, which corresponds to target location $T$ ' (light grey cone), exactly where $T$ would be located if it were placed on horizontal ground. When the ground surface is horizontal, that is $\beta=0^{\circ}, \alpha$ will be equal to $\alpha_{\text {Slope }}$ because $T=T^{\prime}$ targets on flat, horizontal surfaces. The perceived effort, that is, the perceived increase in metabolic cost of traversing the distance, appears to be a parameter for distance perception that depends on both bodily capacities and environmental details (Proffitt, Stefanucci, Banton, \& Epstein, 2003; Stefanucci, Proffitt, Banton, \& Epstein, 2005).

The present work seeks to integrate these two threads of angular declination and effort into a single model of distance perception. Witt and Proffitt (2008) helped to situate effects of effort on distance perception upon the foundation of motor simulations that reflect the "anticipated effort" involved in completing an action to traverse a perceived distance ( $p$. 1480). We tested whether these motor simulations have room for encoding not just the anticipated effort of ascending a slope but also the interaction of effort with slope-dependent reductions in angular declination. We also tested whether training can counteract effort effects and correct distance perception, bringing slope-diminished $\alpha_{P}$ back into alignment with $\alpha$.

\section{Two requirements that motor simulations meet to support distance perception}

Witt and Proffitt (2008) provided a number of helpful features describing the motor simulations implicated in effortdependent distance perception. Two of these are most provocative in how they align with the literature on effort. For instance, the motor simulation "should have access both to the anticipated outcome of the action as well as the energetic costs associated with the action because both of these aspects influence perception" (p. 1480). Witt and Proffitt admitted of a distinction of at least two kinds of effort: one is anticipated, and the other is actually based in the energetics. That is, one is much more cognitive and written in terms of expectations, and the other has much more to do with metabolic cost. This distinction is not only common in the behavioral sciences (Lafargue, Franck, \& Sirigu, 2006), but it comes with the caveat that cognitive systems operate under constraint that effort expended cognitively is effort that cannot be expended metabolically (Kahneman, 1973; Shanks, Rowland, \& Ranger, 2005; Temprado \& Laurent, 2004; Tsang, Velazquez, \& Vidulich, 1996). Under this zero-sum constraint, dual-task evidence shows that physiological energy expenditure suffers with greater mental effort (Sparrow, Bradshaw, Lamoureux, \& Tirosh, 2002; Daniels \& Newell, 2003). Hence, motor simulations appear to carry both of these complementary pieces of information, i.e., the cognitive expectation and the physiological overhead. Witt and Proffitt did not themselves articulate their own recognition of how antagonistic this dualistic nature of effort can become, but we expect that actual effort in acting out the motor simulation might itself have bearings on the integrity of the motor simulation itself or 
at least on the mapping between motor simulation and eventual outcome. We appreciate the difficulty entailed by seemingly contradictory status of effort: energetically defined effort may sap the cognitively defined effort-as-anticipated. Nevertheless, we proceed with the expectation that Witt and Proffitt were correct in opening the motor simulation to two different types of effort. It is not contradictory but rather a consequence of perception-action systems being physicallaw-abiding creatures that must regulate and balance between competing potentials for work.

The second requirement of a motor simulation that we wish to highlight from Witt and Proffitt's (2008) considerations is the explicitly future-directed aspect of motor simulations. "[T] he process [of motor simulation] must be future oriented because people perceive the world in terms of the actions they intend to perform, not those actions they just performed" ( $p$. 1480). That is to say, when they recruit motor simulations to encode anticipated effort, they intend anticipation to mean the forward-looking prediction of what will be. They further cited Jeannerod (2001) as follows "According to Jeannerod, a motor simulation is 'a representation of the future, which includes the goal of the action, the means to reach it, and its consequences on the organism and the external world' (Jeannerod, 2001, p. S103)" (p. 1480). Witt and Proffitt did not specify the length of the prediction window into the future, and they did not specify any sort of updating mechanism by which the novel stimuli might inform a correction or retooling of the motor simulation. We find this omission curious, especially because Loomis et al. (1992) makes plain the need for any internal models of the planned action to traverse a distance to have an updating function. This choice to have motor simulations refer explicitly to the future risks making their appeal to motor simulations too much of a straw person argument, but we take this feature forward in our own test just as we do the two-part aspect of effort.

\section{Articulating effort-based variables in motor simulations}

As noted before, our intent is to investigate whether the motor simulations proposed by Witt and Proffitt (2008) allow for the interaction of effort-based variables with the optical information of angular declination. We have noted above how to calculate the angular declinations, but it remains to articulate the two-part effort and the present-future distinction implicit in Witt and Proffitt's suggestions.

The present-future distinction is much simpler than the two-part definition of effort. Witt and Proffitt (2008) themselves pointed to extensive research in mental rotation (Parsons, 1987), judgments about the ease of a given motion (Frak, Paulingnan, \& Jeannerod, 2001), and explicitly imagining actions (Papaxanthis, Schieppati, Gentili, \& Pozzo, 2002). All of these examples served to illustrate that the time that participants needed to observe, to judge, or to imagine actions corresponded to the actual time that it would have taken or that it actually did take for the participants to enact the movements in actual fact. Witt and Proffitt (2008) never explicitly predicted that observation time should hold similarly for judgment of visually available distances. Hence, although they did cite evidence that time spent imagining walking to a visible target should mimic the time to walk to the target (Papaxanthis, Pozzo, Skoura, \& Schiepatti, 2002), they did not explicitly project the prediction or make the claim that observation time should correspond to the construction of a motor simulation. However, they did suggest that distance judgments were based on motor simulations, and they review in detail that some of the strongest evidence for motor simulations comes from these findings in observation times. If participants engaged in distance perception are in fact using motor simulations of the intended response, then we take upon ourselves the proposal that time spent observing the distance to a visible target should be an important window onto the formation of the motor simulations for distance perception. We hope that this expectation might be in the spirit if not in the letter of Witt and Proffitt (2008).

The question regarding observation times leads us to the recognition that time, much like effort, cuts both ways. There is a long-standing psychological tradition of using temporal latencies as proxy measurements of effort (Fawcett \& Taylor, 2008; Jeannerod, 1995; Petit, Pegna, Mayer, \& Hauert, 2003; Piolat, Olive, \& Kellogg, 2004; Sarampalis, Kalluri, Edwards, \& Hafter, 2009; Trawalter \& Richeson, 2006; Wise \& DeMars, 2006). Amount of time studying a stimulus contributes to a stronger memory trace and so to better recall (de Zubicaray, McMahon, Eastburn, Finnigan, \& Humphreys, 2005; Lehman \& Malmberg, 2013). Indeed, study time is generally thought to contribute to encoding strength, but we are unsure whether Witt and Proffitt (2008) aligned their interest in time spent observing with another interest in the effects of study time improving encoding strength. We are interested in how time spent looking might inform and bolster distance perception, but we also understand that, if we asked participants to enact a response with their eyes closed, we envision time post-observation as jeopardizing veridical distance perception. If we interpret time to observe $\left(t_{\text {Obs }}\right)$ as time spent encoding a motor simulation, time spent responding $\left(t_{\text {Resp }}\right)$ would naturally vary directly with the distance $d$, but longer post-observation times before the participant stops at the judged distance leaves greater occasion for the motor simulation to decay. Motor simulations that allow targeted movements into space become progressively more inaccurate merely $80 \mathrm{~ms}$ after visual information is removed (Bennett, Ashford, \& Elliott, 2003) and continue on the scale of 6 seconds (Binsted, Rolheiser, \& Chua, 2006). Encoding strength or decay should predict how well optical declination angles $\alpha$ and $\alpha_{\text {Slope }}$ determine the angular declination $\alpha_{\mathrm{p}}$ corresponding to the actual response distance $d_{\text {Resp }}$ (Figs. 1 and 2). Hence, we 
chose to articulate the effects of observation time and of response time as interacting with the optical variables of angular declination.

Collecting the response time $t_{\text {Resp }}$ allowed us to quantify both of those effort components that Witt and Proffitt (2008) suggested we should find. To quantify that portion of effort that Witt and Proffitt (2008) called "anticipated effort," we defined simulated speed as the division of the actual distance $d$ observed before participants closed their eyes by the time they took to respond $t_{\text {Resp }}\left(s_{\text {Simu }}=d / t_{\text {Resp }}\right)$. This definition assumes that the response behavior we observe once eyes are closed is the planned output based on previous expectations based in the optical information about distance. To quantify that aspect of effort that has less to do with expectation and sooner reflects the energetic costs of the response behavior, we defined actual speed as the response distance divided by response time $\left(s_{\text {Actual }}=d_{\text {Resp }} / t_{\text {Resp }}\right)$. We anticipated that simulated speed and actual speed might accentuate and diminish, respectively, the contributions of encoded angular declination angles $\alpha$ and $\alpha_{\text {Slope }}$ on the angular declination $\alpha_{\mathrm{p}}$ corresponding to the actual response distance $d_{\text {Resp. }}$. Hence, we included interactions of each speed term with the optical variables $\alpha$ and $\alpha_{\text {Slope }}$.

A customary response modality for asking participants to share their distance perception is blind walking. However, it may be that the response of blind walking introduces needless new complexities that contaminate what would otherwise be a straightforward use of motor simulations. For instance, because of the relationship between eye height $h$ and angular declinations (Figs. 1 and 2), we know that the vertical impulse produced by individual steps of locomotion is a key parameter governing our step-to-step interaction with the angular information in the available optics (Warren, Young, \& Lee, 1986). Hence, blind walking may be structurally at odds with more fundamental relationships between effort and optical information, and the present work seeks to test whether a novel modality less entangled with the optical information of angular declination might iron out the specific effort-based entailments of blind walking and clarify a generic role between optics, effort, and distance perception.

Rope pulling is a novel response modality in distance perception that appears to show similar results to blind walking (Bian \& Andersen, 2013; Philbeck, Woods, Kontra, \& Zdenkova, 2010; Yamamoto \& Hirsch, 2012). We find it particularly interesting, because it includes a formal similarity to blind walking, involving a cyclicity of alternating arm movements similar to the cyclicity of alternating leg movements in bipedal locomotion (Kelso, 1995; Kugler \& Turvey, 1987). It also is intriguing because, for many participants, it is a relatively novel task compared with bipedal locomotion. Perhaps the unfamiliarity of estimating distance that they can no longer see will be matched, for participants, by the relative unfamiliarity of pulling rope to reproduce that distance. With such a novel response modality, it might even be possible to find training effects that would diminish effort effects and, in the process, streamline the perceptual process to a more straightforward, veridical relationship between optical angular declination and perceived distance in which participants learn to ignore $\alpha_{\text {Slope }}$ in favor of generating $\alpha_{\mathrm{p}}$ values closer to $\alpha$.

Our first prediction, the Antagonistic Types of Effort Hypothesis claimed that intended and actual effort (operationalized as $s_{\text {Simu }}$ and $s_{\text {Actual }}$, respectively) would exert opposing effects of optical angles of declination from the horizon, to the sloped surface and to the horizontal unsloped surface, on $\alpha_{\mathrm{p}}$. Specifically, $s_{\text {Simu }}$ would increase the effect of optical variables on $\alpha_{\mathrm{p}}$ through the cognitive processes of rehearsing and consolidating visual representations (Blumenfeld \& Ranganath, 2006; Ranganath, Cohen, \& Brozinsky, 2005) of target distance, whereas $s_{\text {Actual }}$ would diminish the effect of optical variables on $\alpha_{\mathrm{p}}$ due to competition for attentional resources between the task demands imposed by the motor response and the fading visual memory of the stimulus both on the order milliseconds (Slagter, Johnstone, Beets, \& Davidson, 2010) and several seconds (Zhang \& Luck, 2009). Although the anticipated effort and the actual energetic-cost effort were the protagonists of this Antagonistic Types of Effort Hypothesis, it was necessary to include observed distance $d$ and response $t_{\text {Resp }}$ to stand in as control effects. We wanted to guard against attributing spurious statistical effects to effort that were not more simply predictable from these control variables. Decay of visual memory was operationalized as $t_{\text {Resp }}$, thus we predicted that longer response times would result in less reliance on optical information. In the Observation Time Hypothesis, we used Witt and Proffitt's (2008) provocative theorizing that observation time might be a crucial clue to the motor simulations behind distance perception. If observation time $t_{O b s}$ is devoted to constructing an internal motor simulation, then more time spent observing may signify deeper encoding of the optical variables available during observation, namely, angular declination to the slope $\alpha_{\text {Slope }}$, angular declination to the unsloped ground surface $\alpha$, and their interaction in complex terrain. That is, we predict that $t_{O b s}$ will interact with $\alpha_{\text {Slope }}, \alpha$, and $\alpha_{\text {Slope }} \times \alpha$ to strengthen their positive effects on $\alpha_{p}$. Lastly, in the Training Hypothesis training with rope pulling might reduce effort-based effects and leave optical angular declination the more clearly dominant foundation of distance perception judgments.

\section{Method}

In the current study, participants stood at the base of a real hillside and observed a target object placed on the sloped ground. Participants were asked to measure out a length of 
rope held in their hands that corresponded to the perceived distance from their feet to the target object.

\section{Participants}

Ninety participants volunteered through the University of Southern Mississippi's experiment participation website, provided informed consent according to the University of Southern Mississippi's Institutional Review Board, and received course credit for their participation. All participants had normal or corrected-to-normal vision. Participants were randomly assigned to 6 groups of 15 individuals each. There were a total of 48 females and 42 males participating; the average age was 21.2 years (standard deviation [SD] = 5.70). After each experimental session, experimenters measured participants' eye height $(\mathrm{M}=158.5 \mathrm{~cm}, \mathrm{SD}=8.34 \mathrm{~cm})$.

\section{Apparatus}

Experimenters conducted the procedure outdoors in the center of the university campus on a grassy field roughly uniform in texture, horizontal, and flat in orientation for the 0-degree slope and on grassy hills roughly uniform in texture and consistent in angle for the 5- and 10-degree slopes (Fig. 3). Targets were three different-sized orange cones: large (square base $22.86 \mathrm{~cm}$ on each side and height of $30.48 \mathrm{~cm}$ ), medium (square base $13.34 \mathrm{~cm}$ on each side and height of $24.13 \mathrm{~cm}$ ), and small (round base $17.78 \mathrm{~cm}$ in diameter and height of 5.40 $\mathrm{cm})$. Experimenters used a 91.44-m-long measuring tape made of flexible cloth material that participants held and pulled to produce distance estimates. The tape could be wound back and forth into a roll very easily reducing the setup time of each subsequent trial. A stopwatch was used to record observation time and response time. The experimenter used a
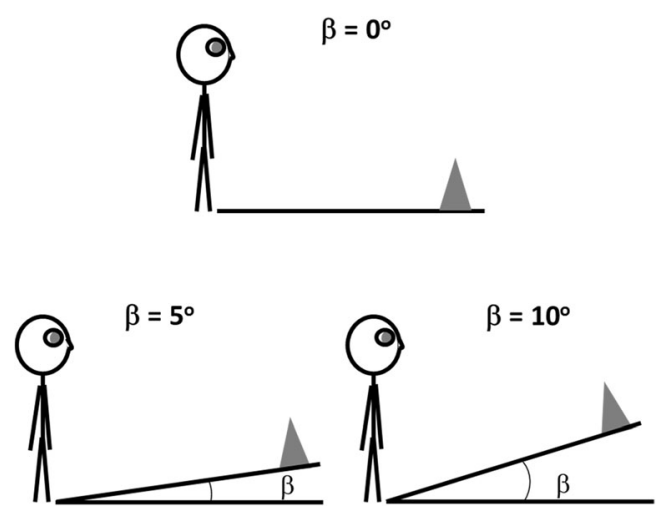

Fig. 3 Top panel: the 0 degree slope condition with participant gazing at target cone. Target cone is placed on the horizontal surface of a grassy field. Bottom panels: the 5- and 10-degree slope conditions with participant gazing at target cone. Target cone is placed on a grassy hill of roughly 5 and 10 degrees, respectively second shorter pocket-size measuring tape to place the cones at each target distance. A brick was placed in front of the participant's feet to indicate the observation location.

\section{Procedure}

Participants were assigned to one of two conditions (Training, No Training) to test distance perception on a sloped surface as registered by blind rope pulling response measures. Both conditions were exactly the same in every aspect except that participants in the second condition received training with rope pulling before using it to register judgments. In all cases, experimenters instructed participants to reproduce the geometric (i.e., straight-line) distance between their feet and the target object. Experimenters instructed participants to take as long as they wished to observe and, instead of instructing them to fixate on a specific location, encouraged participants to scan the area before them without moving their head or body. Eye movements were allowed but not head or body movements. Experimenters monitored participants and recorded no violations (e.g., head turns to look away) to this procedure. Participants were aware that experimenters were timing them, but there were no time limits. Participants were told that the experiment is about judging distance to objects and that they will be asked to measure out the distance by pulling a length of rope corresponding to what they perceive to be the distance between their feet and the target object. Participants were told to wear a blindfold to prevent them from seeing the placement of new target objects in between trials.

Control Condition (No Training) Participants participated in one slope condition only. Experimenters placed blindfolded participants in the middle of the grassy field (for the zero degree condition) or at the bottom of either the 5- or 10 degree hills. Next, experimenters placed the target cone at one of five distances: $1.83,2.44,3.05,3.66$, or $4.27 \mathrm{~m}$. Then, experimenters directed participants to lift up the blindfold to their forehead and to view the target cone placed on the ground surface at a set distance. The experimenter started the stopwatch at the moment when the participant pushed the blindfold up to their forehead and stopped the stopwatch when the participant placed the blindfold back over their eyes. This constituted the observation phase of each trial.

Once a participant had visually inspected the distance from their feet to the target object during the observation phase, he or she then donned the blindfold again and began the response phase of each trial. Experimenters placed a length of flexible measuring tape from a 91.44-m-long spool into the participants' hands. They instructed the participants to pull the tape through their hands until they had pulled out a length of tape that they felt approximated the distance viewed in 
the observation phase. Once the participants were satisfied that their tape pulling had reproduced the viewed distance, experimenters asked the participants to hold the tape between their thumb and forefinger to mark the exact spot they felt approximated the viewed distance. The experimenters then recorded the distance reproduced by the participant as indicated by the length of tape held by the participant. The gradations and scale hatchmarks on the tape were never shown to participants to prevent explicit feedback about accuracy. Response time was measured by a stopwatch starting with a verbal instruction to start pulling the rope, and stopping with the verbal report by the participant who uttered the word "Done!"

Experimenters collected three measurements on every single trial: 1$)$ distance responses $\left(d_{\text {Resp }}\right)$ measured by the amount of tape pulled, as well as durations of time both 1) that each participant took to observe the actual distance $\left(t_{\mathrm{Obs}}\right)$ and 2$)$ that each participant took to reproduce the distances $\left(t_{\text {Resp }}\right)$.

Experimenters presented each distance three times (3 blocks of the five distances) with a randomized presentation order within a 5-trial block, such that each consecutive 5-trial block contained a random presentation of the five different distances. Each participant completed 15 separate trials in total.

At the start of each trial, experimenters gave the participants a 5-digit number to memorize. This task served as a cognitive distraction to prevent participants from counting how many pulls are necessary to reproduce the distance. Participants were required to recall this number at the end of each trial. On average, 4.64 of 5 digits were recalled correctly, which equaled a $92.75 \%$ accuracy rate. This result corresponds to previous reports by Philbeck et al. (2010) in which participants achieved approximately $90 \%$ accuracy.

Experimental Condition (Training) Participants experienced the exact same procedure as in the Control Condition, except that in the Experimental Condition participants received training in the blind rope pulling task before engaging in the actual experiment. In both of two training blocks, participants viewed a target and pulled the measurement tape until they arrived at a paperclip attached to the tape, indicating when to stop pulling the tape to reproduce the distance viewed accurately. For the first training block, participants could see the tape that they pulled. However, the second block of training trials was conducted with the eyes covered so that the only indication for the participant to stop pulling was tactile perception of the paperclip. Both blocks of training trials used the same five distances $(1.52,2.13,2.74,3.35$, and $3.96 \mathrm{~m})$, randomized in each block, just as in nontraining blocks. The procedure was the same as in the Control Condition except that participants were given a recalibration trial (between the 7th and 8th experimental trials) mimicking a first-block training trial, that is, with eyes open and a distance of $3.96 \mathrm{~m}$. The Experimental Condition continued in the same way as the Control Condition from the eighth trial until the end.

\section{Experimental design}

We computed several relevant variables on all trials for each participant: the actual angle of declination $\left(\alpha_{\text {Slope }}\right)$, perceived angle of declination $\left(\alpha_{\mathrm{p}}\right)$, and $\alpha$, the angle of declination corresponding to the projected location $\left(T^{\prime}\right)$ of the target object if it were resting on the horizontal ground at the same distance (Fig. 2).

Multilevel modeling allowed us to test how to predict trialby-trial changes in perception from both temporal and spatial aspects of the perceptual task, such as the contribution of observation time, response time, intended speed, and actual speed to the prediction of perceived distance (Singer \& Willett, 2003). Specifically, our models addressed trial-bytrial distance perception in terms of perceived angular declination $\alpha_{\mathrm{p}}$, derived from the distance response ( $\left.d_{\text {Resp }}\right)$ and eye height $h$.

The variables $t_{\text {Obs }}$ and $t_{\text {Resp }}$ were skewed strongly positively. In order to incorporate them as valid predictors into the linear regression analyses outlined above, we used a naturallogarithmic transform to mitigate this skew. The raw descriptive statistics are reported in Table 1 split by training conditions.

\section{Results}

To provide a straightforward presentation of the data, we plotted perceived distance against actual distance in all experimental conditions. The results are shown in Fig. 4. We conducted a 3 (Slope Angle $\beta: 0,5,10^{\circ}$ ) $\times 2$ (Training: yes, no) $\times 5$ (Distance) repeatedmeasures ANOVA on perceived distance $d_{\text {Resp }}$ as the dependent measure using Slope Angle and Training as between-subjects independent variables. There was a significant main effect of Training, $F(1,84)=34.43$, $p<0.001$, suggesting that perceived distance became more accurate after receiving training with rope pulling. This main effect was further qualified by a significant Distance $\times$ Training interaction, $F(4,336)=16.3, p<$ 0.001 , suggesting that longer distances benefited from training to a larger extent than shorter distances. The interaction revealed that longer distances were more underestimated than shorter distances in the absence of training. No main effects or interactions involving Slope 
Table 1 Descriptive statistics for the effort-based measures grouped by training conditions

\begin{tabular}{|c|c|c|c|c|c|}
\hline & & $t_{\text {Obs }}(\mathrm{s})$ & $t_{\text {Resp }}(\mathrm{s})$ & $s_{\text {Simu }}(\mathrm{m} / \mathrm{s})$ & $s_{\text {Actual }}(\mathrm{m} / \mathrm{s})$ \\
\hline Training & $\mathrm{M}(\mathrm{SD})$ & $8.01(5.04)$ & $9.72(5.19)$ & $0.38(0.17)$ & $0.37(0.19)$ \\
\hline No training & $\mathrm{M}(\mathrm{SD})$ & $9.02(6.71)$ & $9.29(4.51)$ & $0.38(0.16)$ & $0.27(0.15)$ \\
\hline
\end{tabular}

M, mean; SD, standard deviation

Angle were significant indicating that Slope angle did not have a direct influence on distance perception.

Next, we converted all distances into their respective angular declinations ${ }^{1}$, such that physical distance $(d)$ corresponded to physical angular declination $\left(\alpha_{\text {Slope }}\right)$, and perceived distance $\left(d_{\text {Resp }}\right)$ corresponded to perceived angular declination $\left(\alpha_{\mathrm{p}}\right)$. These variables were used in multilevel mixed effects models in subsequent analyses. In all models presented in the paper, the error terms included trials nested within individual subjects, accounting for differences in individual slopes and intercepts. Model 1 tested the effects of optical variables on visual information for visually guided distance perception (Loomis et al., 1992). Specifically, the model looked at the effects of $\alpha_{\text {Slope }}, \alpha$, and $\alpha_{\text {Slope }} \times \alpha$. The model returned significant positive main effects for both $\alpha_{\text {Slope }}$ and $\alpha(B=0.8536$, standard error $[S E]=0.1619, p<0.0001 ; B=0.8850, S E=$ $0.1978, p<0.0001$, respectively). Thus, perceived angle of declination $\alpha_{\mathrm{p}}$ increased with the actual angular declination with respect to the sloped terrain $\alpha_{\text {Slope }}$, but also with increases of angular declination to the horizontal ground $\alpha$ (even though the horizontal ground was not visible to participants in the 5 and 10 degree slope conditions). In addition, the model returned a significant negative $\alpha_{\text {Slope }} \times \alpha$ interaction ( $B=$ $-0.0121, \mathrm{SE}=0.0023, p<0.0001)$, suggesting that the interaction served to weaken the effects of both optical variables. The results of Model 1 are presented in Table 2.

Model 2 included all the effort-based variables $\left(t_{\text {Obs }}, t_{\text {Resp }}\right.$, $\left.s_{\text {Actual }}, s_{\text {Simu }}\right)$, as well as all of their interactions with the optical variables $\alpha_{\text {Slope }}, \alpha$, and $\alpha_{\text {Slope }} \times \alpha$ from Model 1. Adding these 20 new predictors resulted in changes in -2LL Deviance, $\chi^{2}(20)=1766.03, p<0.0001$, which indicated a significant improvement in model fit (Table 3). Thus, the inclusion of effort-related predictors into the model significantly improved the prediction of perceived angular declination below the horizon and thus, perceived distance. The inclusion of effortrelated variables, however, rendered all main effects from Model 1 nonsignificant and turned only two interactions

\footnotetext{
${ }^{1}$ Distances were converted into angular declinations in order to match the dimensions of the candidate informational variable (angular declination) and perception (perceived angular declination). We followed the procedure of Ooi, Wu and He (2006) who used the same conversion to express the accuracy of perceived angular declination. Another advantage of conversion is that angular declination is defined (and thus scaled) by eye height, thus making all angular declination measures intrinsic to individual observers. This way, individual differences are directly incorporated into angular measures.
}

among optics and actual effort significant (see Table 4 for details). Specifically, the significant $s_{\text {Actual }} \times \alpha(B=-4.688$, $\mathrm{SE}=0.5419, p<0.0001)$ interaction was further qualified by the significant $s_{\text {Actual }} \times \alpha_{\text {Slope }} \times \alpha(B=0.0605$, SE $=$ $0.0108, p<0.0001$ ) interaction.

Model 3 sought to further test for moderating effects of effort-based variables on the optical variables utilized as visual information for distance perception in the context of training rope pulling (referring to the Antagonistic Types of Effort Hypothesis and the Training Hypothesis). That is, the new predictors encompassed Training as well as all of its interactions with existing predictors in Model 2, totaling 24 in all. Adding 24 new predictors led to significantly large changes in -2LL deviance, $\chi^{2}(24)=335.98, p<0.0001$, which indicates a significant improvement in model fit. Therefore, the incorporation of training as a predictor into the model significantly improved the prediction of perceived angular declination below the horizon and thus, perceived distance. The results of the model comparisons are presented in Table 5.

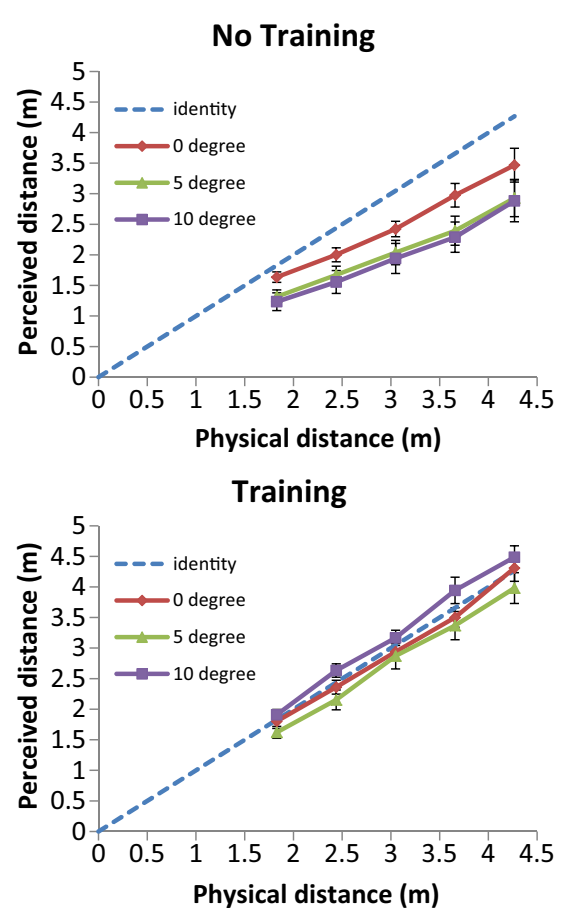

Fig. 4 Perceived distance $\left(d_{\text {Resp }}\right)$ as a function of physical distance (d) and slope angle ( $\beta$ : 0-, 5-, and 10-degree hills). Top panel shows the group that received no training on rope pulling. Bottom panel indicates the results of the group that received training on rope pulling. Error bars correspond to \pm 1 standard error 
Table 2 All individual predictors in Model 1

\begin{tabular}{llll}
\hline Predictor & $B$ & SE & $p$ \\
\hline Intercept & -5.598 & 2.329 & 0.02 \\
$\alpha_{\text {Slope }}$ & 0.8536 & 0.1619 & $<0.0001$ \\
$\alpha$ & 0.8850 & 0.1978 & $<0.0001$ \\
$\alpha_{\text {Slope }} \times \alpha$ & -0.0121 & 0.0023 & $<0.0001$ \\
\hline
\end{tabular}

Next, we looked at the specific effects and interactions included in Model 3. As illustrated in Table 6, the main effect of $\alpha$ observed in Model 1 did not prove significant in Model 3 $(B=1.923, \mathrm{SE}=1.464, p=0.19)$. However, the main effect of $\alpha_{\text {Slope }}$ remained significant $(B=-3.583, \mathrm{SE}=1.226, p<$ $0.004)$, which indicates that perceived angular declination was influenced by the visual information available to the observer. Qualifying this main effect, there was a significant Training $\times \alpha_{\text {Slope }}$ interaction $(B=6.457, \mathrm{SE}=1.786, p<$ 0.0003 ), which indicated that training facilitates the observer's reliance on the available optical information. Taken together, these findings confirmed the assumptions set forth in the Antagonistic Types of Effort Hypothesis and in the Training Hypothesis. Namely, observers would rely on the visual information made available $\left(\alpha_{\text {Slope }}\right)$ and that training would promote reliance on this information.

The Observation Time Hypothesis pertained to any effects of $t_{\mathrm{Obs}}$ on perceived angle of declination. There were no significant effects of $t_{\mathrm{Obs}}$ on any of the included variables. This finding would seem to cast doubt on the usefulness of motor simulation during stimulus observation. We performed bootstrap-based power analyses, essentially, to check whether 1,000 resamplings of the data with replacement would reliably return nonzero coefficient estimates $80 \%$ of the time (Yuan \& Hayashi, 2003). All significant effects were adequately powered (i.e., power $>80 \%$ ), but the test for predictor $t_{O b s}$ was not. Taken together, far from being proof of a null effect, this contrast suggests that the effect size for the $t_{O b s}$ must be quite small compared with that for other factors. In addition, actual physical distance $(d)$ did not contribute to the use of optical variables and did not influence perception in meaningful ways, as indicated by the absence of statistically significant effects of optics and physical distance in Models 2 and 3.

The Antagonistic Types of Effort Hypothesis posited that greater $t_{\text {Resp }}$ would reduce the effect of optical variables on
Table 4 Coefficients from Model 2. All interactions of optics with effort-based variables were included

\begin{tabular}{llll}
\hline Predictor & $B$ & SE & $p$ \\
\hline Intercept & 12.82 & 21.84 & 0.56 \\
Effects of optical variables on $\alpha_{\mathrm{p}}$ & & \\
$\alpha_{\text {Slope }}$ & 0.2593 & 0.8831 & 0.77 \\
$\alpha$ & 1.775 & 0.9619 & 0.07 \\
$\alpha_{\text {Slope }} \times \alpha$ & -0.0182 & 0.0232 & 0.43
\end{tabular}

Effects of observation time on use of optical variables for $\alpha_{\mathrm{p}}$

$\begin{array}{llll}t_{\text {Obs }} & 0.5970 & 1.879 & 0.75 \\ t_{\text {Obs }} \times \alpha_{\text {Slope }} & -0.1040 & 0.0920 & 0.26 \\ t_{\text {Obs }} \times \alpha & 0.0490 & 0.1017 & 0.63 \\ t_{\text {Obs }} \times \alpha_{\text {Slope }} \times \alpha & 0.0012 & 0.0022 & 0.60\end{array}$

Controlling for effect of observed distance on use of optical variables

$\begin{array}{llll}d & -0.9023 & 3.454 & 0.79 \\ d \times \alpha_{\text {Slope }} & -0.0573 & 0.1386 & 0.68 \\ d \times \alpha & 0.1976 & 0.1770 & 0.26 \\ d \times \alpha_{\text {Slope }} \times \alpha & -0.0066 & 0.0046 & 0.15\end{array}$

Effects of response time on use of optical variables for $\alpha_{\mathrm{p}}$

$\begin{array}{llll}t_{\text {Resp }} & -4.251 & 9.692 & 0.66 \\ t_{\text {Resp }} \times \alpha_{\text {Slope }} & 0.4699 & 0.4058 & 0.25 \\ t_{\text {Resp }} \times \alpha & -0.5844 & 0.4529 & 0.20 \\ t_{\text {Resp }} \times \alpha_{\text {Slope }} \times \alpha & 0.0033 & 0.0111 & 0.77\end{array}$

Effects of simulated speed on use of optical variables for $\alpha_{\mathrm{p}}$

$\begin{array}{llll}s_{\text {Simu }} & -3.460 & 26.11 & 0.89 \\ s_{\text {Simu }} \times \alpha_{\text {Slope }} & 0.3167 & 1.070 & 0.77 \\ s_{\text {Simu }} \times \alpha & 1.972 & 1.215 & 0.10 \\ s_{\text {Simu }} \times \alpha_{\text {Slope }} \times \alpha & -0.0235 & 0.0297 & 0.43\end{array}$

Effects of actual speed on use of optical variables for $\alpha_{\mathrm{p}}$

$\begin{array}{llll}s_{\text {Actual }} & 8.867 & 9.174 & 0.33 \\ s_{\text {Actual }} \times \alpha_{\text {Slope }} & 0.3560 & 0.4566 & 0.44 \\ s_{\text {Actual }} \times \alpha & -4.688 & 0.5419 & <0.0001 \\ s_{\text {Actual }} \times \alpha_{\text {Slope }} \times \alpha & 0.0605 & 0.0108 & <0.0001\end{array}$

perceived angular declination, because the information would decay with time. While there was a significant main effect of $t_{\text {Resp }}(B=-28.9698, \mathrm{SE}=14.2784, p<0.043)$ and a significant interaction of $t_{\text {Resp }} \times \alpha_{\text {Slope }}(B=1.673, \mathrm{SE}=0.5297, p<$ $0.002)$, the most meaningful significant finding was a negative interaction of Training $\times t_{\text {Resp }} \times \alpha_{\text {Slope }}(B=-2.397, \mathrm{SE}=$ $0.825, p<0.004)$. Considered in isolation, the positive $t_{\text {Resp }}$

Table 3 Predictors composing Model 1 and Model 2

\begin{tabular}{lllr}
\hline Model & Highest-order interactions & Number of added predictors & $\chi^{2}$ \\
\hline 1 & $\alpha \times \alpha_{\text {Slope }}$ & & $p$ \\
2 & $\begin{array}{l}t_{\text {Obs }} \times \alpha \times \alpha_{\text {Slope }}+t_{\text {Resp }} \times \alpha \times \alpha_{\text {Slope }}+ \\
d \times \alpha \times \alpha_{\text {Slope }}+ \\
s_{\text {Simu }} \times \alpha \times \alpha_{\text {Slope }}+s_{\text {Actual }} \times \alpha \times \alpha_{\text {Slope }}+\alpha \times \alpha_{\text {Slope }}\end{array}$ & 20 & 1766.03 \\
& & & $<0.0001$ \\
\end{tabular}


Table 5 Predictors composing Model 2 and Model 3

\begin{tabular}{llll}
\hline Model & Highest-order interactions & Number of added predictors & $\chi^{2}$ \\
\hline 2 & $t_{\text {Obs }} \times \alpha \times \alpha_{\text {Slope }}+$ \\
& $t_{\text {Resp }} \times \alpha \times \alpha_{\text {Slope }}+$ \\
& $d \times \alpha \times \alpha_{\text {Slope }}+$ \\
& $s_{\text {Simu }} \times \alpha \times \alpha_{\text {Slope }}+s_{\text {Actual }} \times \alpha \times \alpha_{\text {Slope }}+$ \\
& $\alpha \times \alpha_{\text {Slope }}$ \\
& Training $\times t_{\text {Obs }} \times \alpha \times \alpha_{\text {Slope }}+$ & & \\
& Training $\times t_{\text {Resp }} \times \alpha \times \alpha_{\text {Slope }}+$ \\
& Training $\times d \times \alpha \times \alpha_{\text {Slope }}+$ \\
& Training $\times s_{\text {Simu }} \times \alpha \times \alpha_{\text {Slope }}+$ \\
& Training $\times s_{\text {Actual }} \times \alpha \times \alpha_{\text {Slope }}+$ Training $\times \alpha \times \alpha_{\text {Slope }}$ & 24 & 335.98 \\
& & & $<0.0001$ \\
&
\end{tabular}

$\times \alpha_{\text {Slope }}$ would have resulted in poor performance across the board. Training qualified this interaction in a negative fashion, suggesting that poor performance was relegated to the condition without training. Because memory decay was operationalized by response time, these findings indicated that training may have neutralized any potential effect of memory decay on the visual trace, which is consistent with both the Antagonistic Types of Effort Hypothesis and the Training Hypothesis. Essentially, the effects of memory decay weakened the influence of optics only in the context of the observer being trained, perhaps because training made up for memory decay by "artificially" propping up perception via feedback. Figure 5 plots the summation of these effects for the entire observed range of $t_{\text {Resp }}$ for low (i.e., first quartile), medium (i.e., median), and high (i.e., third quartile) values of $\alpha_{\text {Slope }}$.

The Antagonistic Types of Effort Hypothesis also stated that $s_{\text {Simu }}$ would increase the effects of the optical variables on perceived angular declination. The data showed a positive interaction of $s_{\text {Simu }} \times \alpha_{\text {Slope }}(B=3.436, \mathrm{SE}=1.3948$, $p<0.014)$. However, there also was a negative interaction of Training $\times s_{\text {Simu }} \times \alpha_{\text {Slope }}(B=-5.252, \mathrm{SE}=2.170, p<$ 0.016). The differentiation of an otherwise positive $s_{\text {Simu }} \times \alpha_{\text {Slope }}$ interaction with Training diminished said positive interaction. Because simulated speed was an operationalization of intended effort, interpreted as an accentuator of optics through rehearsal and active engagement of representations, this indicated that training neutralized any potential benefit from rehearsing and engaging representations during observation and rendered the planned management of energetic resources irrelevant, which is consistent with the Training Hypothesis. In short, training weakened the alleged enhancement of optics by planned effort, perhaps making its contribution unnecessary. Figure 6 plots the threeway interaction across training conditions for the entire observed range of $s_{\text {Simu }}$ for low (i.e., first quartile), medium (i.e., median), and high (i.e., third quartile) values of $\alpha_{\text {Slope }}$.

In addition, the Antagonistic Types of Effort Hypothesis predicted that $s_{\text {Actual }}$ would reduce the effect of the optical variables due to perceptuomotor interference from the response task. There was no observed main effect of $s_{\text {Actual }}$ on perceived angular declination; however, there were several significant interactions: $s_{\text {Actual }} \times \alpha_{\text {Slope }}(B=3.603, \mathrm{SE}=$ $0.6989, p<0.0001), s_{\text {Actual }} \times \alpha(B=-7.746, \mathrm{SE}=0.7860$, $p<0.0001), s_{\text {Actual }} \times \alpha_{\text {Slope }} \times \alpha(B=0.0604, \mathrm{SE}=0.0177$, $p<0.0006)$, Training $\times s_{\text {Actual }} \times \alpha_{\text {Slope }}(B=-4.147, \mathrm{SE}=$ $0.958, p<0.001)$, and Training $\times s_{\text {Actual }} \times \alpha(B=2.616, \mathrm{SE}=$ $1.120, p<0.020$ ). Of these interactions, the most comprehensive and meaningful is the highest order, negative interaction of Training $\times s_{\text {Actual }} \times \alpha_{\text {Slope }}$, which indicated that training annulled the effect of interference between motor activity and attention to internal representations on available optics. This suggested that training perhaps moves the perceptual system towards diminishing reliance on optics and is consistent with the Training Hypothesis. The pattern and direction of the effects for the Training $\times s_{\text {Actual }} \times \alpha_{\text {Slope }}$ interaction was essentially the same as for Training $\times s_{\text {Simu }} \times \alpha_{\text {Slope }}$ interaction. Interestingly, the positive interaction of Training $\times s_{\text {Actual }}$ $\times \alpha$ indicated that during training increased effort was spent on amplifying the role of optics with respect to the horizontal ground $(\alpha)$. As we have seen in the previous interaction, actual effort diminished influence on $\alpha_{\text {Slope }}$. Training with feedback made performance in the rope pulling task more accurate and thus consistent with optics with respect to the horizontal ground. This work was done by actual effort, while divesting attention from $\alpha_{\text {Slope }}$ and was consistent with the Training Hypothesis.

\section{Null effects of distance $d$ and of observation time $t_{\text {Obs }}$ is not the consequence of higher-order interactions}

An outstanding concern may be that the null effects for salient features of this model are less due to small effect sizes and sooner attributable to multicollinearity from a large model with strongly correlated fixed effects. Multicollinearity can inflate error terms and thus cloak significant effects in nonsignificant garb (Kutner, Nachtsheim, \& Neter, 2004). To show how that multicollinearity does not explain the patterns of significance, we include one of the simplest models for which $d$ and $t_{\text {Obs }}$ were nonsignificant (Table 7). First, we point to the 
Table 6 Coefficients from Model 3. All interactions with effort-based variables were included; however, only significant interactions with Training are presented to save space

\begin{tabular}{lcll}
\hline Predictor & $B$ & $\mathrm{SE}$ & $P$ \\
\hline Intercept & 69.563 & 32.543 & 0.03 \\
Effects of optical variables on & $\alpha_{\mathrm{p}}$ & & \\
$\quad \alpha_{\text {Slope }}$ & -3.583 & 1.226 & $<0.004$ \\
$\alpha$ & 1.923 & 1.464 & 0.19 \\
$\alpha_{\text {Slope }} \times \alpha$ & 0.0451 & 0.0340 & 0.19 \\
Training $\times \alpha_{\text {Slope }}$ & 6.457 & 1.786 & $<0.0003$
\end{tabular}

Effects of observation time on use of optical variables for $\alpha_{\mathrm{p}}$

$\begin{array}{llll}t_{\text {Obs }} & -1.416 & 2.451 & 0.56 \\ t_{\text {Obs }} \times \alpha_{\text {Slope }} & -0.0064 & 0.1173 & 0.96 \\ t_{\text {Obs }} \times \alpha & 0.1186 & 0.1351 & 0.38 \\ t_{\text {Obs }} \times \alpha_{\text {Slope }} \times \alpha & -0.0019 & 0.0029 & 0.51\end{array}$

Controlling for effect of observed distance on use of optical variables

$\begin{array}{llll}d & 4.781 & 4.939 & 0.33 \\ d \times \alpha_{\text {Slope }} & -0.2519 & 0.1724 & 0.14 \\ d \times \alpha & 0.0471 & 0.2647 & 0.86 \\ d \times \alpha_{\text {Slope }} \times \alpha & -0.0053 & 0.0065 & 0.41\end{array}$

Effects of response time on use of optical variables for $\alpha_{\mathrm{p}}$

$\begin{array}{llll}t_{\text {Resp }} & -28.9698 & 14.2784 & <0.043 \\ t_{\text {Resp }} \times \alpha_{\text {Slope }} & 1.673 & 0.5297 & <0.002 \\ t_{\text {Resp }} \times \alpha & -0.0605 & 0.7051 & 0.93 \\ t_{\text {Resp }} \times \alpha_{\text {Slope }} \times \alpha & -0.0240 & 0.0160 & 0.13 \\ \text { Training } \times t_{\text {Resp }} \times \alpha_{\text {Slope }} & -2.397 & 0.825 & <0.004\end{array}$

Effects of simulated speed on use of optical variables for $\alpha_{\mathrm{p}}$

$\begin{array}{llll}s_{\text {Simu }} & -47.9775 & 36.3977 & 0.19 \\ s_{\text {Simu }} \times \alpha_{\text {Slope }} & 3.436 & 1.3948 & <0.014 \\ s_{\text {Simu }} \times \alpha & 2.0711 & 1.7799 & 0.24 \\ s_{\text {Simu }} \times \alpha_{\text {Slope }} \times \alpha & -0.0743 & 0.0403 & 0.07 \\ \text { Training } \times{ }_{\text {Simu }} \times \alpha_{\text {Slope }} & -5.252 & 2.170 & <0.016\end{array}$

Effects of actual speed on use of optical variables for $\alpha_{\mathrm{p}}$

\begin{tabular}{|c|c|c|c|}
\hline$s_{\text {Actual }}$ & -0.1877 & 14.0493 & 0.99 \\
\hline$s_{\text {Actual }} \times \alpha_{\text {Slope }}$ & 3.603 & 0.6989 & $<0.0001$ \\
\hline$s_{\text {Actual }} \times \alpha$ & -7.746 & 0.7860 & $<0.0001$ \\
\hline$s_{\text {Actual }} \times \alpha_{\text {Slope }} \times \alpha$ & 0.0604 & 0.0177 & $<0.0006$ \\
\hline Training $\times{ }_{s_{\text {Actual }}} \times \alpha_{\text {Slope }}$ & -4.147 & 0.958 & $<0.001$ \\
\hline Training $\times{ }{ }_{\text {Actual }} \times \alpha$ & 2.616 & 1.120 & $<0.020$ \\
\hline
\end{tabular}

significant effects of $t_{\text {Resp }}$ and $s_{\text {simu }}$, each $p<0.0001$. The correlation of $t_{\text {Resp }}$ and $s_{\text {simu }}$ is $r=0.87$. So, collinearity does not prevent the estimation of significant effects. Next, consider the relatively weaker correlation of $d$ with $\alpha, r=0.79$. However, despite the strong correlation, the statistical model does not respond equally to each of these predictors. Removal of $d$ leads to a nonsignificant increase in the model's deviance (i.e., $-2 \log$-likelihood [LL]), $\chi^{2}(1)=1.03, p=0.31$. On the other hand, removing $\alpha$ leads to a much more catastrophic increase in the model's $-2 \mathrm{LL}$ deviance, $\chi^{2}(1)=188.73, p<$ 0.0001 . It may be puzzling for $d$ not to have an effect in a

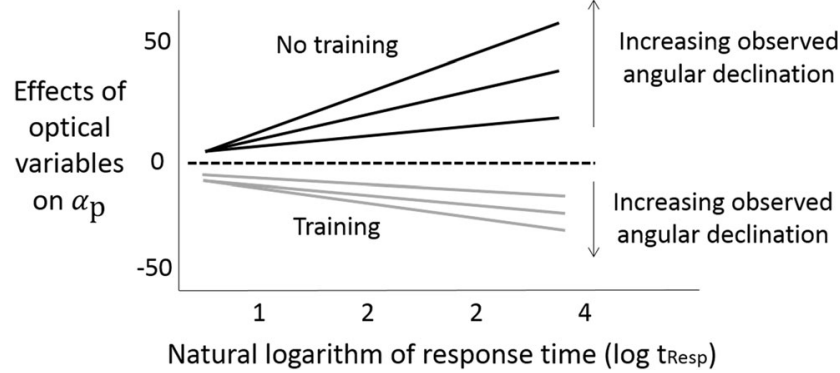

Fig. 5 Three-way Training $\times t_{\text {Resp }} \times \alpha_{\text {Slope }}$ interaction. Plot uses the estimated coefficients in Model 3 to illustrate how effects of optical variables on perceived angular declination $\alpha_{p}$ change without training (black lines) and with training (grey lines). The dashed horizontal line defines the zero-mark indicating no effect on optical variables. Greater response time leads to more negative effects of optical variables on perceived angular declination in the training condition, whereas greater response time results in more positive effects of optical variables on $\alpha_{\mathrm{p}}$ in the absence of training. The lines farther from the dashed horizontal line (i.e., the zero) indicate the effects of training (or lack thereof) for progressively larger observed angular declinations (i.e., first quartile, median, and third quartile). The arrow and text at the bottom right of the figure indicates the progression of these plotted effects with increasing observed angular declination

distance-perception experiment, but it should be recalled that the statistical model addresses perceived distance in terms of the angular declination $\alpha_{p}$. The fact that we are able to reason as well about metric distance as about optical angles does not actually prohibit that distance perception might depend upon one and not both sort of geometries, especially not within a single statistical model. Also, perceptual systems are quite comfortable to align their judgments with non-specifying information (Withagen, 2004), and there is likewise precedence for distance estimates that do not depend on distance (Ziemer, Branson, Chihak, Kearney, Cremer, \& Plumert, 2013). As for $t_{\mathrm{Obs}}$, despite being the noisier of the two latencies, it appears that the greater variance in $t_{O b s}$ does not contain any stronger

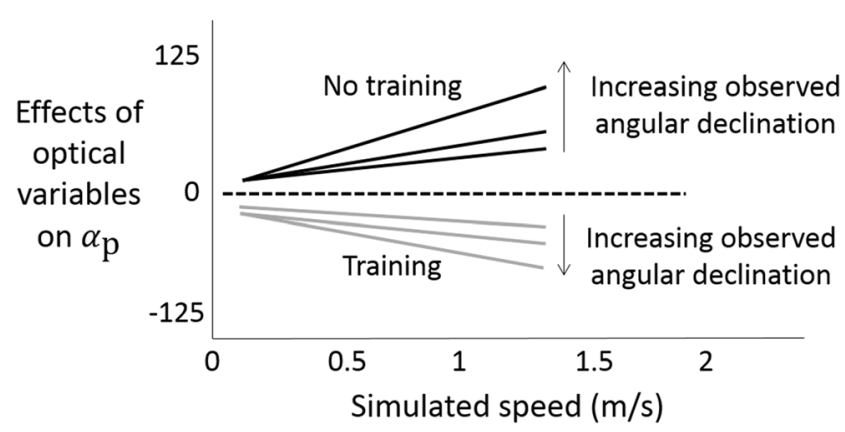

Fig. 6 Three-way Training $\times \mathrm{S}_{\text {Simu }} \times \alpha_{\text {Slope }}$ interaction. Plot uses the estimated coefficients in Model 3 to illustrate how effects of optical variables on perceived angular declination $\alpha_{p}$ change without training (black lines) and with training (grey lines). Dashed horizontal line defines the zero-mark indicating no effect on optical variables. Greater simulated speed leads to more negative effects of optical variables on perceived angular declination in the training condition, whereas greater simulated speed results in more positive effects of optical variables on $\alpha_{\mathrm{p}}$ in the absence of training 
Table 7 Main-effects-only model of $\alpha_{\mathrm{p}}$ that exhibits nonsignificant effects of $d$ and $t_{\mathrm{Obs}}$

\begin{tabular}{llll}
\hline Predictor & $B$ & SE & $P$ \\
\hline Intercept & 32.38 & 3.99 & $<0.0001$ \\
Trial & -0.04 & 0.06 & 0.51 \\
Training & -3.32 & 0.64 & $<0.0001$ \\
$\alpha$ & 0.78 & 0.06 & $<0.0001$ \\
$d$ & -0.47 & 0.46 & 0.31 \\
$t_{\text {Obs }}$ & 0.28 & 0.24 & 0.25 \\
$t_{\text {Resp }}$ & -6.95 & 0.87 & $<0.0001$ \\
$s_{\text {Simu }}$ & 41.69 & 2.38 & $<0.0001$ \\
$s_{\text {Actual }}$ & -67.08 & 1.41 & $<0.0001$ \\
\hline
\end{tabular}

relationship with the response measure $\alpha_{p}$ or with the other predictors, $r \mathrm{~s}<0.11$.

\section{Discussion}

The present research sought to elaborate on Hajnal et al.'s (2014) investigation of the interaction between optical and effort variables on distance perception across varying grades of sloped surfaces. We tested three hypotheses. First, we sought to replicate the effects of effort-related variables previously demonstrated by Hajnal et al. (2014). Second, we sought to test whether rope pulling might have revealed the effect of longer observation times on distance judgments. Third, we sought to test the hypothesis that training would make perception more accurate, diminishing effort-based effects and situating distance perception more firmly on the foundation of purely optical variables. Our results supported the Antagonistic Types of Effort Hypothesis and the Training Hypothesis but failed to support the Observation Time Hypothesis. In more general terms, we view our work as broadening the scope of the ABDH hypothesis and generalizing to complex terrains such as hills and ramps. Although our results have offered limited evidence for such generalization, the emphasis on angular declinations as useful optical information has remained powerful even if we have not vindicated all of its original expectations. This failure may be due to the observation by Proffitt and Linkenauger (2013) that perception is a phenotypic expression of both bodily capabilities and perceptual information, a richly updated notion of Gibson's (1979) concept of affordance. Simply put, ADBH does not fully generalize due to its failure to account for the influence of effort on perception.

The Antagonistic Types of Effort Hypothesis was supported in a broad set of interactions found through multilevel modeling (Model 2). The positive $t_{\text {Resp }} \times \alpha_{\text {Slope }}$ interaction indicated the presence of detrimental effect of memory decay on optics. Consistent with the Antagonistic Types of Effort Hypothesis, planned effort facilitated reliance on optics as demonstrated by the positive $s_{\text {Simu }} \times \alpha_{\text {Slope }}$ interaction. Attention split among the demands of the actual response task and the supposedly stored representations had differential effects on optics packed into the positive $s_{\text {Actual }} \times \alpha_{\text {Slope }} \times \alpha$ interaction. This effect contradicted the Antagonistic Types of Effort Hypothesis in the absence of accounting for the effects of training that will be considered in the context of the Training Hypothesis.

The Observation Time Hypothesis found no support from the present results. The present work found no significant effects of $t_{\text {Obs }}$ whatsoever, casting some doubt upon the presence and usefulness of motor simulation during observation. Our current findings are similar to the findings of Hajnal et al. (2014), particularly in that they both failed to substantiate the claims of the Observation Time Hypothesis regarding the effects of $t_{\mathrm{Obs}}$ on perceived angle of declination. Although it is reasonable to believe that time spent encoding a variable is related to the richness of the encoded visual trace, observation times appeared to play no real role in determining perception of distance.

Results supported the Training Hypothesis as well. Training reduced the effects of simulated speed $s_{\text {Simu }}$ on perceived angular declination, and suppressed the effect of memory decay on optics. Training differentially affected reliance on optics in the context of potential interference with the rope pulling response task by weakening reliance on visually available, but nonveridical optics ( $\left.\alpha_{\text {Slope }}\right)$, and by strengthening reliance on veridical optics defined with respect to the horizontal ground $(\alpha)$. In sum, it seems that training is, at a minimum, richly supplementing perception, but may eliminate mental representations or motor programs implicated in the task.

As mentioned before, training appeared to contribute to interactions with optical and effort-based variables in a way that counteracted untrained optical-effort interactions (e.g., Training $\times s_{\text {Actual }} \times \alpha_{\text {Slope }}$ and Training $\left.\times s_{\text {Actual }} \times \alpha\right)$. The negative Training $\times s_{\text {Actual }} \times \alpha_{\text {Slope }}$ interaction can be broken down into two simpler interactions: $s_{\text {Actual }} \times \alpha_{\text {Slope }}$, analyzed separately, with and without training. In the absence of training there was a significant positive interaction between optics and actual effort. During training this interaction became nonsignificant. The diminishing positive interaction allowed the emergence of the significant negative Training $\times s_{\text {Actual }} \times$ $\alpha_{\text {Slope }}$ interaction. This finding is consistent with the Antagonistic Types of Effort Hypothesis and the Training Hypothesis, because it indicated the progressively weakening role of actual effort in facilitating reliance on optics. The Training Hypothesis predicted that reliance on optics would become stronger with training. The current interaction was in nuanced agreement with this hypothesis. Although reliance on optics $\left(\alpha_{\text {Slope }}\right)$ was suppressed by training, the significant positive interaction of training with optics defined with respect to the horizontal ground $(\alpha)$ tells us that not all optical variables were suppressed by training. The positive Training $\times s_{\text {Actual }} \times$ $\alpha$ interaction would seem to indicate that increased effort was 
spent on amplifying optics with respect to the horizontal ground during training. Therefore, the data suggested that actual effort diminished influence on $\alpha_{\text {Slope }}$. At the same time training with feedback made perception more accurate, and thus consistent with optics defined with respect to the horizontal ground $(\alpha)$. This work was done by actual effort, while diverting attention from $\alpha_{\text {Slope }}$ and is consistent with the Training Hypothesis. Specifically, in the context of these two significant interactions with Training, it is apparent that the visual system shifted from reliance on visually available optical information $\left(\alpha_{\text {Slope }}\right)$ to reliance on visually not available optical information $(\alpha)$. It may be the case that training with feedback breaks the natural link between information that specifies target location $\left(\alpha_{\text {Slope }}\right)$ and perception $\left(\alpha_{\mathrm{p}}\right)$. Even though $\alpha_{\mathrm{p}}$ (as reliant on information) resulted in consistently inaccurate responses, it was nevertheless lawfully based on specifying information.

\section{Effort as a measure of functional equivalence among visually guided actions}

Philbeck et al. (2010) have compared rope pulling with measurements of blind walking (Loomis et al., 1992) and showed that the two measures are equivalent. Our present contribution has provided further evidence for this equivalence. The picture that emerged paints visually guided actions as complex sensorimotor responses where visual stimulation is no longer available during the response. Both Hajnal et al. (2014) and the present investigation revealed that the complexity of visually guided actions may include a whole host of perceptual and cognitive processes spanning multisensory stimulation, detection of information, creation and storage of visual and motor representations for later usage, attention, motor control, and many others. We hypothesized that some if not most of these cognitive processes can be categorized as expressions of planned and current effort, that is, as scheduled budgeting and spending of energetic resources of the organism with respect to environmental task demands. We found rope pulling to be equivalent to blind walking in almost all aspects of how effort is expressed and utilized by organisms. This suggests that functional equivalence (see Stephen \& Hajnal, 2011, for an illustrative example), being a hallmark feature of perceptionaction systems, can be effectively studied by way of keeping tabs on how effort changes during perception and visually guided action.

\section{Complementarity of effort and acquisition of perceptual competence}

Training with feedback is a typical example of acquisition of perceptuomotor competence. In our study we discovered that training effects go towards minimizing the role of effort, even those part of it that contribute to mental simulation. We do feel that training draws the participants' focus away from some sort of "internal" or "self-based" metric of performance and invites them to sample a new pool of information from the experimenter whose evaluation pulls them away from tracking effort. As recent research by Withagen (2004) suggests there are many "non-specifying variables" that feedback draws the participants away from, and they move through an "information space" (Jacobs \& Michaels, 2007; Jacobs, Vaz, \& Michaels, 2012) away from the non-specifying effort aspects to the accurate source of information (provided by the experimenter). Experimenter feedback anchors participant performance in a measurement frame outside themselves - more reliable than what their own impression might tell participants left to their own devices (Kelty-Stephen \& Eddy, 2015). Training over the time scale of an entire experiment may gradually come to reshape the effects of effort at the short scales of time and may gradually redirect effort appropriately and minimally towards more accurate responses.

In this latter sense, training and effort complement each other in that training provides new experiences to bring about a novel configuration of the perception-action system. The attenuating effect of training does not necessarily suggest that distance perception never relies on mental simulations, but it might suggest that training helps to minimize and maybe eventually eliminate the need for mental simulations.

The apparently small effect size for $t_{O b s}$ may pose either a minor challenge to motor-simulation theories of distance perception or a major one. The minor challenge will simply involve elaborating the notion of motor simulation beyond Witt and Proffitt's (2008) direct transplanting of Jeannerod's (2001) idea that motor simulation is strictly future-oriented. Representational accounts need not suffer from the strawperson status that such a future-only orientation is permitted in a motor simulation. Certainly, there must be a mechanism by which participants can update the motor simulation (Loomis et al., 1992). The absence of significant effects for $t_{\mathrm{Obs}}$ is not problematic for motor simulations provided that motor simulations are not strictly future-oriented but can actually address how current changes influence future plans, allowing the construction of the motor simulation to extend past the observation period and into the response period. ${ }^{2}$ However this challenge might be resolved, we may need to overcome Witt and

\footnotetext{
${ }^{2}$ In addition to the possibility that mental simulation could extend beyond the observation period, it also is possible that simulation did take place during the observation time but that this measure included time looking around campus, time noticing friends or people walking past, etc. and this noise might have masked/overshadowed the portion of observation time that reflects the time needed for mental simulation. As such, this noise may have reduced the usefulness of observation time as a measure of mental simulation, and we look forward to learning of other measures that might more aptly capture the construction of the mental simulation.
} 
Proffitt's (2008) requirement that "people perceive the world in terms of the actions they intend to perform, not those actions they just performed" (p. 1480). If Witt and Proffitt are correct that motor simulations are compatible with this view, then motor simulations are different from representational structure that encode past information, and the motor-simulation model may require further representational vehicles to carry sufficient information. The larger challenge would come from the larger question of whether or not representational encoding of the optical variables is employed at all to generate the visual traces believed to be used in the response task. As soon as we admit that the construction of motor simulations might extend past the observation time, the challenge from nonrepresentational perceptual theories is that it may be no less worthwhile to query, as well, all other non-encoding structures across the resources of the perceiving-acting organism that likewise persist beyond the observation time (Turvey, 2007; Turvey \& Fonseca, 2014).

If Witt and Proffitt's (2008) interest in observation times when discussing the motor-simulation support for effort effects on distance perception have been apt, then it is worth stepping back and considering alternate interpretations of observation time. For instance, observation time may more straightforwardly describe the exploration that animal behavior research (Andersson, 1978) and human visual perception research (Gilchrist, North, \& Hood, 2001; Klein \& MacInnes, 1999) have cast as foraging which is certainly a function of anticipated energy expenditure. Therefore, the two interpretations may be equivalent in that both associate latencies with effort, regardless of the perceptual or cognitive process that underlies it.

The more ecological and animal-referential way of interpreting the present work may extend a firmer plank into the foundations for a more thoroughly Gibsonian view of distance perception. There have been many attempts to phrase the problems of distance perception, as well as of cousin fields spatial and place perceptions, in Gibsonian terms of effort with much less emphasis on representational baggage as the driving force (Harrison \& Turvey, 2010; Isenhower et al., 2012; Turvey et al., 2009). Certainly, even in the animal literature, the most competitive accounts of distance perception remain representational, appealing to "step counting" or "path integration" as mechanisms even for ants (Grah, Wehner, \& Ronacher, 2005; Wittlinger, Wehner, \& Wolf, 2007). Appreciating that ants' representational capacities must be rudimentary at best, a more thoroughgoing Gibsonian approach would be to discard representation from the set of explanations altogether. It would be an extreme step, but so far, we do not find the effects of observation time that Witt and Proffitt (2008) noted in previous demonstrations of motor simulations. We persist in finding that observation time has but meager (and in our experience, nonsignificant) relationship with perceived distance. Instead, we find the larger contribution of effects spanning several different time scales at once, ranging from the trial-by-trial response latencies to the training with the response metric over the time scale of the experiment. If we are not to take the extreme step of jettisoning, then we will need to press representational accounts to explain the representation bases for the other effects. The burden for representational accounts is also for explaining why we need these somewhat cumbersome objects.

The challenge for dumping representational accounts entirely would be the explanation of how it is that once-sighted objects can persist for informing the subsequently blind response for registering a distance judgment. After all, this challenge is why the need for representations seems plain to many researchers interested in distance perception. Any single latency, whether spent observing or spent responding, is a remarkably broad and nonspecific indicator of attention and effort. Whatever cognitive effort might be brought to bear in the formation of a representation or motor simulation surely depends not on time spent looking. Rather, what we see in our present results is that distance perception is the product of interactions of events across many different time scales, in which long-term training ends up streamlining and improving the efficacy of short-term effort expended on each trial. It is plausible that training at least simplifies that sort of mental simulation needed, perhaps reducing it to what little an ant might need. On the other hand, on any given trial and in a variety of tasks, the subtle motor variability of postural sway as people look out in front of them (even under the instructions to stand still) exhibits statistical signature of interactions across time scales, and those within-trial signatures of interactions across scales actually predict the use of current visual information, both during the same trial (Palatinus, KeltyStephen, Kinsella-Shaw, Carello, \& Turvey, 2014) and several trials later, long after the retina has lost the original image (Kelty-Stephen, \& Dixon, 2014).

So, within the time spent observing, the body is doing rather interesting - even though subtle - things to explore the visual scene with the eyes but also with the head and torso all at once, even if the simple duration of observation persists in contributing very little of what Witt and Proffitt (2008) suggested it would. Our results suggest that the interesting things that bodies do within trial will of course change with the impact of interesting things that the experimenter can provide with feedback on responses across many trials. That the different response metrics of blind rope-pulling and blindwalking (Hajnal et al., 2014) both seem to enlist these interactions across time scales for functionally equivalent uses of optical variables may recommend accounts of effort that emphasize less the representational aspects of distance perception and more so the dynamics of systems that can blend multiple time scales. If capacities for representation 
construction for distance perception extend beyond observation time, we welcome the reconciliation of approaches that might lean equally well on the non-representational structures that develop across such long ranges of time as well.

\section{References}

Andersson, M. (1978). Optimal foraging area: Size and allocation of search effort. Theoretical Population Biology, 13(3), 397-409.

Bennett, S. J., Ashford, D., \& Elliott, D. (2003). Intermittent vision and one-handed catching: The temporal limits of binocular and monocular integration. Motor Control, 7, 378-387.

Bian, Z., \& Andersen, G. J. (2013). Aging and the perception of egocentric distance. Psychology and Aging, 28(3), 813-825.

Binsted, G., Rolheiser, T., \& Chua, R. (2006). Decay in visuomotor representations for control. Journal of Motor Behavior, 38, 82-87.

Blumenfeld, R. S., \& Ranganath, C. (2006). Dorsolateral prefrontal cortex promotes long-term memory formation through its role in working memory. Journal of Neuroscience, 18, 916-925.

Daniels, G. L., \& Newell, K. M. (2003). Attentional focus influences the walk-run transition in human locomotion. Biological Psychology, 63, 163-178.

de Zubicaray, G. I., McMahon, K. L., Eastburn, M. M., Finnigan, S., \& Humphreys, M. S. (2005). fMRI evidence of word frequency and strength effects in recognition memory. Cognitive Brain Research, 24, 587-598.

Fawcett, J. M., \& Taylor, T. L. (2008). Forgetting is effortful: Evidence from reaction time probes in an item-method directed forgetting task. Memory \& Cognition, 36, 1169-1181. doi:10.3758/MC.36.6. 1168

Frak, V. G., Paulingnan, Y., \& Jeannerod, M. (2001). Orientation of the opposition axis in mentally simulated grasping. Experimental Brain Research, 136, 120-127.

Gibson, J. J. (1950). The Perception of the Visual World. Boston: Houghton Mifflin Company.

Gibson, J. J. (1979). The Ecological Approach to Visual Perception. Boston: Houghton Mifflin.

Gilchrist, I. D., North, A., \& Hood, B. (2001). Is visual search really like foraging? Perception, 30(12), 1459-1464

Grah, G., Wehner, R., \& Ronacher, B. (2005). Path integration in a threedimensional maze: Ground distance estimation keeps desert ants Cataglyphis fortis on course. Journal of Experimental Biology, 208(21), 4005-4011.

Hajnal, A., Bunch, D. A., \& Kelty-Stephen, D. G. (2014). Going for distance and going for speed: Interactions of effort with optical variables shape visual information for visually-guided distance perception from observation to response. Attention, Perception, \& Psychophysics, 76, 1015-1035.

Harrison, S. J., \& Turvey, M. T. (2010). Place learning by mechanical contact. Journal of Experimental Biology, 213, 1436-1442.

Isenhower, R. W., Kant, V., Frank, T. D., Pinto, C. M., Carello, C., \& Turvey, M. T. (2012). Equivalence of human odometry by walk and run is indifferent to self-selected speed. Journal of Motor Behavior, 44(1), 47-52

Jacobs, D. M., \& Michaels, C. F. (2007). Direct learning. Ecological Psychology, 19(4), 321-349.

Jacobs, D. M., Vaz, D. V., \& Michaels, C. F. (2012). The learning of visually guided action: An information-space analysis of pole balancing. Journal of Experimental Psychology: Human Perception and Performance, 38(5), 1215-1227.
Jeannerod, M. (1995). Mental imagery in the motor context. Neuropsychologia, 33, 1419-1432.

Jeannerod, M. (2001). Neural simulation of action: A unifying mechanism for motor cognition. Neurolmage, 14, S103-S109.

Kahneman, D. (1973). Attention and effort. Englewood Cliffs: Prentice Hall.

Kelso, J. A. S. (1995). Dynamic patterns. Cambridge: MIT Press.

Kelty-Stephen, D. G., \& Dixon, J. A. (2014). Interwoven fluctuations during intermodal perception: Fractality in head sway supports the use of visual feedback in haptic perceptual judgments by manual wielding. Journal of Experimental Psychology: Human Perception and Performance, 40(6), 2289-2309.

Kelty-Stephen, D. G., \& Eddy, C. L. (2015). Self-trained perception need not be veridical: Striking can exaggerate judgment by wielding and can transfer exaggeration to new stimuli. Attention, Perception, \& Psychophysics, 77(6), 1854-1862.

Klein, R. M., \& MacInnes, W. J. (1999). Inhibition of return is a foraging facilitator in visual search. Psychological Science, 10(4), 346-352.

Kugler, P. N., \& Turvey, M. T. (1987). Information, natural law, and the self-assembly of rhythmic movement. Hillsdale: Erlbaum.

Kutner, M. H., Nachtsheim, C. J., \& Neter, J. (2004). Applied linear regression models. Irwin: McGraw-Hill.

Lafargue, G., Franck, N., \& Sirigu, A. (2006). Sense of motor effort in patients with schizophrenia. Cortex, 42, 711-719.

Lehman, M., \& Malmberg, K. J. (2013). A buffer model of encoding and temporal correlations in retrieval. Psychological Review, 120, 155189.

Loomis, J., DaSilva, J., Fujita, N., \& Fukusima, S. (1992). Visual space perception and visually directed action. Journal of Experimental Psychology: Human Perception and Performance, 18(4), 906-921.

Loomis, J., DaSilva, J., Philbeck, J. W., \& Fukusima, S. (1996). Visual perception of location and distance. Current Directions in Psychological Science, 5(3), 72-77.

Ooi, T. L., Wu, B., \& He, Z. J. (2001). Distance determined by the angular declination below the horizon. Nature, 414, 197-200.

Ooi, T. L., Wu, B., \& He, Z. J. (2006). Perceptual space in the dark affected by the intrinsic bias of the visual system. Perception, 35(5), 605-624.

Palatinus, Z., Kelty-Stephen, D. G., Kinsella-Shaw, J., Carello, C., \& Turvey, M. T. (2014). Haptic perceptual intent in quiet standing affects multifractal scaling of postural fluctuations. Journal of Experimental Psychology: Human Perception and Performance, 40(5), 1808-1818

Papaxanthis, C., Pozzo, T., Skoura, X., \& Schiepatti, M. (2002a). Does order and timing in performance of imagined and actual movements affect the motor imagery process? The duration of walking and writing task. Behavioral Brain Research, 134, 209-215.

Papaxanthis, C., Schieppati, M., Gentili, R., \& Pozzo, T. (2002b). Imagined and actual arm movements have similar durations when performed under different conditions of direction and mass. Experimental Brain Research, 143, 447-452.

Parsons, L. M. (1987). Imagined spatial transformation of one's body. Journal of Experimental Psychology: General, 116, 172-191.

Petit, L. S., Pegna, A. J., Mayer, E., \& Hauert, C. A. (2003). Representation of anatomical constraints in motor imagery: Mental rotation of a body segment. Brain \& Cognition, 51, 95-101.

Philbeck, J. W., Woods, A. J., Kontra, C., \& Zdenkova, P. (2010). A comparison of blindpulling and blindwalking as measures of perceived absolute distance. Behavioral Research Methods, 42(1), $148-160$.

Piolat, A., Olive, T., \& Kellogg, R. T. (2004). Cognitive effort during note taking. Applied Cognitive Psychology, 19, 291-312.

Proffitt, D. R. (2006). Embodied perception and the economy of action. Perspectives on Psychological Science, 1(2), 110-122. 
Proffitt, D. R., Bhalla, M., Gossweiler, R., \& Midgett, J. (1995). Perceiving geographic slant. Psychonomic Bulletin \& Review, 2, 409-428.

Proffitt, D. R., Stefanucci, J., Banton, T., \& Epstein, W. (2003). The role of effort in distance perception. Psychological Science, 14, 106-112.

Proffitt, D. R., \& Linkenauger, S. A. (2013). Perception viewed as a phenotypic expression. In W. Prinz, M. Beisert, \& A. Herwig (Eds.), Action science: Foundations of an emerging discipline (pp. 171-198). Cambridge, MA: MIT Press.

Ranganath, C., Cohen, M. X., \& Brozinsky, C. J. (2005). Working memory maintenance contributes to long-term memory formation: Neural and behavioral evidence. Journal of Cognitive Neuroscience, 17, 994-1010.

Rieser, J. J., Ashmead, D., Talor, C., \& Youngquist, G. (1990). Visual perception and the guidance of locomotion without vision to previously seen targets. Perception, 19, 675-689.

Sarampalis, A., Kalluri, S., Edwards, B., \& Hafter, E. (2009). Objective measures of listening effort: Effects of background noise and noise reduction. Journal of Speech, Language, and Hearing Research, 52, $1230-1240$

Schnall, S., Zadra, J. R., \& Proffitt, D. R. (2010). Direct evidence for the economy of action: Glucose and the perception of geographic slant. Perception, 39, 464-482.

Sedgwick, H. A. (1983). Environmental-centered representations of spatial layout: Available visual information from texture and perspective. In A. Rosenthal \& J. Beck (Eds.), Human and Machine Vision (pp. 425-458). New York: Academic.

Shanks, D. R., Rowland, L. A., \& Ranger, M. S. (2005). Attentional load and implicit sequence learning. Psychological Research, 69, 369-382.

Sinai, M. J., Ooi, T. L., \& He, Z. J. (1998). Terrain influences the accurate judgment of distance. Nature, 395, 497-500.

Singer, J. D., \& Willett, J. B. (2003). Applied longitudinal data analysis: Modeling change and event occurrence. New York: Oxford University Press.

Slagter, H. A., Johnstone, T., Beets, I. A. M., \& Davidson, R. J. (2010). Neural competition for conscious representation across time. PLoS ONE, 5, e10556.

Sparrow, W. A., Bradshaw, E. J., Lamoureux, E., \& Tirosh, O. (2002). Ageing effects on the attention demands of walking. Human Movement Science, 21, 961-972.

Stefanucci, J. K., Proffitt, D. R., Banton, T., \& Epstein, W. (2005). Distances appear different on hills. Perception \& Psychophysics, 67, 1052-1060.

Stephen, D. G., \& Hajnal, A. (2011). Transfer of calibration between hand and foot: Functional equivalence and fractal fluctuations. Attention, Perception, \& Psychophysics, 73, 1302-1328. doi:10.3758/ s13414011-0142-6

Stoper, A., \& Cohen, M. (1986). Judgments of eye level in light and in darkness. Perception and Psychophysics, 40, 311-316.

Temprado, J.-J., \& Laurent, M. (2004). Attentional load associated with performing and stabilizing a between-persons coordination of rhythmic limb movements. Acta Psychologica, 115, 1-16.
Thomson, J. A. (1983). Is continuous visual monitoring necessary in visually guided locomotion? Journal of Experimental Psychology: Human Perception and Performance, 9(3), 427-443.

Trawalter, S., \& Richeson, J. A. (2006). Regulatory focus and executive function after interracial interactions. Journal of Experimental Social Psychology, 42, 406-412.

Tsang, P. S., Velazquez, V. L., \& Vidulich, M. A. (1996). The viability of resource theories in explaining time-sharing performance. Acta Psychologica, 91, 175-206.

Turvey, M. T. (2007). Action and perception at the level of the synergies. Human Movement Science, 26, 657-697.

Turvey, M. T., \& Fonseca, S. T. (2014). The medium of haptic perception: A tensegrity hypothesis. Journal of Motor Behavior, 46, 143-187.

Turvey, M. T., Romaniak-Gross, C., Isenhower, R. W., Arzamarski, R., Harrison, S., \& Carello, C. (2009). Human odometer is gaitsymmetry specific. Proceedings of the Royal Society of London B: Biological Sciences, rspb20091134.

Warren, W. H., Young, D. S., \& Lee, D. N. (1986). Visual control of step length during running over irregular terrain. Journal of Experimental Psychology: Human, Perception, \& Performance, 12, 259-266.

Wise, S. L., \& DeMars, C. E. (2006). An application of item response time: The effort-related model. Journal of Education Measurement, $43,19-38$.

Withagen, R. (2004). The pickup of nonspecifying variables does not entail indirect perception. Ecological Psychology, 16(3), 237-253.

Witt, J. K., \& Proffitt, D. R. (2008). Action-specific influences on distance perception: A role for motor simulation. Journal of Experimental Psychology: Human Perception and Performance, 34, 1479-1492. doi:10.1037/a0010781

Wittlinger, M., Wehner, R., \& Wolf, H. (2007). The desert ant odometer: A stride integrator that accounts for stride length and walking speed. Journal of Experimental Biology, 210(2), 198-207.

Wu, B., He, Z. J., \& Ooi, T. L. (2007). Inaccurate representation of the ground surface beyond a texture boundary. Perception, 36, 703721.

Yamamoto, N., \& Hirsch, D. A. (2012). "What" versus "how" in nonvisual whole-body movement. In N. Miyake, D. Peebles \& R. P. Cooper (Eds.), Proceedings of the 34th Annual Conference of the Cognitive Science Society, Cognitive Science Society (pp. 25582563). Japan: Sapporo.

Yuan, K. H., \& Hayashi, K. (2003). Bootstrap approach to inference and power analysis based on three test statistics for covariance-structure models. British Journal of Mathematical and Statistical Psychology, 56, 93-101.

Zhang, W., \& Luck, S. J. (2009). Sudden death and gradual decay in visual working memory. Psychological Science, 20, 423-428.

Ziemer, C. J., Branson, M. J., Chihak, B. J., Kearney, J. K., Cremer, J. F., \& Plumert, J. M. (2013). Manipulating perception versus action in recalibration tasks. Attention, Perception, \& Psychophysics, 75, $1260-1274$. 